\title{
Destellos culturales entre España y Estados Unidos a través de la prensa estadounidense (1945-1952)
}

\author{
Javier MAESTRO BÄCKSBACKA \\ Universidad Complutense de Madrid \\ jmaestro@ccinf.ucm.es \\ Antonia Sagredo SANTos \\ Universidad Nacional de Educacion a Distancia \\ asagredo@flog.uned.es
}

Recepción: 16 de febrero de 2010 / Revisión: 28 de marzo de 2010

Aceptación: 29 de abril de 2010 / Publicación: diciembre de 2010

\begin{abstract}
RESUMEN
Las relaciones culturales entre España y los Estados Unidos en el período comprendido entre el final de la Segunda Guerra Mundial y la firma de los Pactos de Madrid de 1953 estuvieron supeditadas a la estrategia política diseñada por el Departamento de Estado norteamericano y la actitud del régimen franquista. Estas relaciones tuvieron su reflejo en la prensa norteamericana coetánea, siendo el cuerpo principal de nuestra investigación. En esos años había que superar las dificultades que existían para poder establecer unas relaciones culturales permanentes, a pesar de ello, se registraron algunas iniciativas que permitieron mantener un flujo de españoles que entraron en contacto con la cultura, vida y sociedad estadounidense y, simultáneamente, grupos de norteamericanos, principalmente estudiantes, visitaron España.
\end{abstract}

Palabras clave: Relaciones culturales, Estados Unidos, España, prensa estadounidense, 1945-1952.

\section{Cultural Flashes between Spain and the United States in American Periodicals (1945-1952)}

\begin{abstract}
Spanish-American cultural relations during the period between the end of WWII and the signature of the Military Alliance in 1953 were conditioned by the State Department's policy towards Spain and the corresponding attitude of Franco-Spain. These cultural intercourses were reported in American periodicals, and this paper has mainly made use of these periodicals as its main research source. In spite of the almost unsurmountable difficulties to attain normalcy in cultural relations, steps were taken so that a number of Spaniards got in touch with American society, culture and values, and conversely, an increasing number of Americans, mainly students, visited Spain.
\end{abstract}

Keywords: Cultural relations, the United Status, Spain, American Press, 1945-1952.

SUMARIO: 1. Introducción. 2. Sintonías y disonancias. 3. Presencia cultural de Estados Unidos en España. 4. Intercambios culturales. 5. Iniciativas culturales norteamericanas y españolas. 6. Libros sobre España publicados en Estados Unidos, 1945-1952. 7. La industria cinematográfica estadounidense en España. 8. Conclusiones. 9. Referencias Bibliográficas.

${ }^{1}$ Este artículo se ha realizado en el marco del Proyecto de Investigación HAR2009-13284 del Plan Nacional I+D+I (2009-2011) del Ministerio de Ciencia e Innovación. 


\section{INTRODUCCIÓN}

Buena parte de las noticias culturales, provenientes de agencias de prensa y de corresponsales acreditados en España, aparecen en los diarios, semanarios y revistas dirigidas a una opinión pública ilustrada -New York Times, Washington Post, New York Journal, Chicago Herald Tribune, Christian Science Monitor, Look-. Una prensa cuya tirada nacional sobrepasaba los 200.000 ejemplares y que ejercía, en consecuencia, una influencia indudable entre las elites políticas y en la opinión pública informada. Esta prensa partía de posiciones ideológicas plurales, aunque, en general, de corte liberal-democrático, y recogía en sus páginas cómo eran entendidas y cómo se desarrollaron las relaciones culturales con la España franquista, pero también con la cultura española republicana que cultivaban los exilados españoles, tanto en Estados Unidos como en otros países. En definitiva, el enfoque de la prensa estadounidense permite ver cómo se percibían los vínculos culturales entre ambos países desde la perspectiva de la opinión pública informada de Estados Unidos.

Este trabajo tiene como objetivo principal complementar los numerosos estudios ya realizados sobre las relaciones culturales entre ambos países en el período comprendido entre 1945 y 1952, partiendo del análisis de cómo la prensa estadounidense contemplaba dichas relaciones y cómo las transmitía a la opinión pública. En este estudio se han utilizado fuentes hemerográficas relevantes, habiendo consultado prácticamente toda la prensa de ámbito nacional de Estados Unidos, aportando una visión todavía inédita a las investigaciones relacionadas con las relaciones culturales entre España y Estados Unidos de la época.

A continuación, se presenta una contextualización de dichas relaciones dentro de un marco más amplio, aunque sea de forma muy general, para verificar en qué medida la prensa estadounidense recogía en sus titulares y noticias los nexos culturales existentes entre Estados Unidos y España en los años objeto de este estudio.

\section{SINTONÍAS Y DISONANCIAS}

En 1951, el ex embajador de Estados Unidos en España -Carlton J.H. Hayesdecía que las diferencias culturales entre España y Estados Unidos eran evidentes, y que éstas estaban condicionadas por la historia y por un entorno que las harían perdurar a lo largo de un futuro distante. "Por ello [afirmaba] no sólo es necesario que ambos pueblos aprendan a conocerse mejor, sino que sean capaces de respetar sus diferencias" 2 . A su juicio esas diferencias culturales podían difuminarse,

[...] si un creciente número de personas influyentes -educadores, comunicadores, eclesiásticos, empresarios y hombres de letras- se interesaran, a fin de arrinconar los mitos y tópicos al uso, por reunir y difundir en cada país información sólida y positiva sobre el otro. En Estados Unidos deberíamos tener más historia de España en nuestros centros educativos, más viajes a España, más aprecio por la literatura y el arte de España. Los españoles por su parte deberían tener más historia de

2 HAYes, 1951, pp. 190-191. 
Estados Unidos en sus universidades, viajar más a Estados Unidos y tener un mejor conocimiento de nuestro idealismo ${ }^{3}$.

Valgan estas palabras proféticas para explicar esas diferencias culturales que, en el caso español, nutrieron un antiamericanismo con ribetes fundamentalistas, particularmente presente en los años objeto de estudio. Salvador de Madariaga ${ }^{4}$, por su parte, en su obra de 1927 que tuvo numerosas reediciones, "Ingleses, franceses y españoles", no hizo sino reproducir, como tantos otros, una supuestamente superada idea sobre las "señas de identidad culturales", propias de cada comunidad nacional". Debido a que el contexto histórico concreto de ese periodo coincidía con una exaltación de los valores propios de cada comunidad nacional y a que la mentalidad y opinión pública de la época eran especialmente receptivas a tales consideraciones, lo cierto es que esas perspectivas dieron alas a estados de opinión etnocéntricos a ambos lados del Atlántico. Así, en Estados Unidos, Walter Schubart en su obra "Russia and Western Man" (1950), caracterizaba a los españoles como

[...] desprovistos de talento para el pensamiento analítico o sistemático. Consideran los mitos, los sueños o la poesía como formas más adecuadas para conocer la verdad [...] Los tesoros intelectuales de España no se encuentran en la filosofía académica, sino en la poesía, el misticismo y en la cruda realidad de su gente 6 .

La etapa que abordamos puede que sea el periodo donde la disparidad cultural entre ambos países haya sido especialmente llamativa desde cualquier perspectiva. España se contemplaba en Estados Unidos, más que nunca antes, como un país exótico, cerrado, represivo e intolerante; un pueblo atrasado y sometido a un sistema totalitario. Los obstáculos políticos que se interponían eran de hecho tan insuperables que buena parte de las imágenes diferenciadoras se centraron obligadamente en ellos.

En efecto, el régimen de Franco era entonces un proscrito debido a su innegable identificación con el fascismo. Estados Unidos votó en consecuencia en 1946, junto con la comunidad internacional, a favor del aislamiento internacional de España y de la retirada de embajadores 7 . Esa situación de distanciamiento extremo perduró oficialmente hasta 1950, aunque de hecho las aproximaciones extraoficiales se fueron escalonando desde 1948. Si las relaciones políticas se deterioraron, no lo hicieron menos las culturales, reducidas a su mínima expresión como trataremos de poner de manifiesto en este artículo. No obstante, Estados Unidos se inclinó por no romper del todo los nexos culturales con España. Buena prueba de ello es la apuesta de iniciar una penetración cultural "autónoma" por medio de instituciones como la Casa

3 Ibidem, p. 189.

${ }^{4}$ Sobre el pensamiento del autor, véase GonZález Cuevas, 1989, pp. 145-181.

5 En el periódico en español, La Prensa de Nueva York, aparece el 23 de junio de 1947 un artículo en esa línea firmado por Salvador De Madariaga titulado "El genio español" (La Prensa de Nueva York contaba, según Editor \& Publisher del 8 de junio de 1950, con 500.000 lectores y unos ingresos por publicidad estimados en 400 millones de dólares).

6 Recogido en Washington Daily News, Washington. 26-VIII-1950.

7 Véase MaEstro BäcKsbackA - SAgredo SAntos, 2010, pp. 20-80. 
Americana, inaugurada en Madrid en 1943 y posteriormente provista de ramificaciones en otras ciudades como Barcelona y Valencia. Prevaleció la idea de que era posible y necesario atraer hacia los valores estadounidenses a los segmentos de la población española proclives a una convergencia cultural y política. En los primeros años -hasta 1948- las iniciativas culturales norteamericanas con respecto a España se dirigieron preferentemente hacia las clases medias ilustradas, poco o nada comprometidas con el régimen franquista. Pero segar la hierba bajo los pies de una dictadura era una apuesta arriesgada si no iba acompañada de una voluntad real de cambiar la pobreza del monolitismo cultural de la España franquista. Las consideraciones políticas planearon siempre sobre la estrategia cultural, de forma que una titubeante política de wait and see [ya veremos] no podía sino cosechar escasos avances para una aproximación.

Así, la Casa Americana no pasó de ser un deslumbrante escaparate de la American way of life que en la práctica tendió escasos puentes de interacción cultural. Estados Unidos experimentó problemas semejantes de "conexión" con buena parte de los países latinoamericanos. Desde Estados Unidos España ha sido, por lógica, siempre contemplada como una potencia cultural rival en América Latina. A ello alude, por ejemplo, Lorenzo Delgado al afirmar que

[...] los dirigentes franquistas consideraban al país norteamericano un adversario a combatir para recuperar el ascendiente español sobre los países hispanos del otro lado del Atlántico. La Hispanidad tenía en el panamericanismo a su principal antagonista ${ }^{8}$.

En palabras de Emmet J. Hughes, Agregado de Prensa de la Embajada de Estados Unidos en Madrid (1942-1945),

España, América Latina y Estados Unidos forman un triángulo geográfico e histórico, y la cruda geometría nos dice que cada ángulo del triángulo queda afectado por cambios en los otros dos 9 .

Por ello, por ejemplo, durante la Segunda Guerra mundial, Estados Unidos vio con preocupación las actividades culturales e ideológicas que desplegaron los grupos falangistas al servicio de las potencias del Eje en varios países latinoamericanos, a pesar de la insignificancia de estas actividades. Desde Estados Unidos se interpretó esta amenaza cultural y política de las potencias del Eje como un peligro potencial ${ }^{10}$, lo que motivó el despliegue, en todo el mundo hispanohablante, de servicios de propaganda para contrarrestar o al menos neutralizar tales actividades antinorteamericanas con España como uno de los epicentros ${ }^{11}$. De aquí también las presiones que se

8 Delgado Gómez-Escalonilla, 2009a, p. 107.

9 Hughes, 1945, p. 287.

10 FolTz, 1948, p. 149, cifra en 20.000 el total de miembros de Falange Exterior en América latina. Añade que la potente emisora, similar a Radio Leipzig, entregada por los alemanes a la agencia EFE e instalada en Arganda, sería posteriormente utilizada por Radio Nacional para sus emisiones a América Latina, a ello contribuyó también la agencia Prensa Mundial, financiada asimismo por los alemanes.

11 Hughes, 1947, p. 232 afirma que "the United States became the target of the most vicious attacks. Arriba (May 3, 1939) set the keynote for a hostile Hispanidad policy in Latin America in an 
ejercieron por parte de la opinión pública estadounidense y de su prensa ${ }^{12}$, así como desde la embajada de Estados Unidos en Madrid, contra la presencia ideológica falangista en las diversas instancias políticas del régimen franquista ${ }^{13}$.

Entre 1943-1945 se alcanzaron los objetivos propuestos, que consistían en neutralizar mediante presión al régimen español al calor de los avances de las potencias aliadas. Así, desde 1944 el Consejo de la Hispanidad, principal semillero de la idea de la "voluntad de Imperio", aparcó también su virulento antiyanquismo para apostar por un verbalismo estrictamente hispánico, volcado en la comunidad cultural hispana asentada en el idioma, la raza, la historia, la religión y la "Madre Patria"14.

\section{PRESENCIA CULTURAL DE ESTADOS UNIDOS EN ESPAÑA}

En 1947, la prensa estadounidense recogía unas declaraciones del encargado de negocios norteamericano en España, Paul T. Culbertson, en las que afirmaba que:

Parte del objetivo diplomático en España es desarrollar las relaciones culturales entre los Estados Unidos y el país del Generalísimo Francisco Franco [...] Otros dos gobiernos, el británico y francés, habían adoptado actitudes similares hacia España. Mientras desaprobaban el gobierno de Franco, estaban desarrollando de forma activa unas relaciones culturales con el pueblo español ${ }^{15}$.

article laboriously headlined, "End of the Spanish War Entails for South American Peoples a Possible Change in Their political Conceptions". The official Party organ explained that this "change" would be brought about "with damage to the democracies and proclaimed in a moral climate far removed from the present, the doctrine of the unity of the Hispanic World".

12 Ibídem, p. 254. Este autor refleja en su obra que la "public opinion in the United States, especially of the liberals and leftists who persistently denounced the maintenance of diplomatic relations with the Franco regime even during wartime, generally was loud in its acclaim of the Anglo-American decision to impose an oil embargo on Spain in February of 1944. This was the only occasion when the liberal American press applauded the State Department's policy toward Spain, for abandoning "appeasement" in favour of a "firm" or "tough" action against Falangist Spain".

13 Hughes, 1947, dedica nada menos que los capítulos 4 y 5 del libro a la Falange y, en términos tan condenatorios, que no dejaron de formar parte del arsenal de acusaciones de la administración de Harry S. Truman contra la dictadura franquista. Stanley G. PAINE publicaría en 1965 su libro sobre la Falange.

14 Sin embargo, todavía el 23 de septiembre de 1951, el periodista Duncan Aikman, especialista estadounidense en América Latina y autor del libro The All-American Front, envía al Washington Post un artículo titulado "Los fascistas latinos [de Europa y América] ganan oportunidades en una conferencia a celebrar en Río de Janeiro", convocada para el 12 de octubre, día de la Raza. En el diseño de este Bloque Latino el autor ve la mano larga de Argentina y España y advierte que "España podría utilizar esta plataforma más amplia para propulsar su propaganda de Hispanidad, la misma que ha venido impulsando contra Estados Unidos en el resto de las Américas desde los días del rey Alfonso". Y añade que los Estados Unidos, desde el punto de vista de la Hispanidad, "es una nación herética protestante compuesta de bárbaros incultos, ávidos de dólares, que en periodos de crisis, en tiempos de paz y de guerra, han intentado hacerse con el control de los recursos económicos de América Latina por medio de un imperialismo avaricioso y sin escrúpulos". El autor finalmente hace un recuento de gobiernos democráticos y autoritarios en América Latina.

15 Dosch-Fleurot, Arno: "U. S. Boosts Cultural relations in Spain", Christian Science Monitor, Boston, 10-VI-1947. 
En junio de 1942, los servicios centrales de la Office of War Information (OWI) decidieron establecer una representación en España ${ }^{16}$. A finales de ese mes llegó a Madrid Emmet J. Hughes ${ }^{17}$, quien dirigió las operaciones del OWI hasta diciembre de este mismo año. A partir de entonces se hizo cargo del trabajo William Patterson. El principal objetivo de la sucursal madrileña de la OWI era lanzar la propaganda bélica en España ${ }^{18}$. Estados Unidos ya tenía establecidos centros culturales en diferentes países, fruto de las labores de la OWI, desde los que pretendía promover múltiples actividades para acercar la cultura americana al ciudadano europeo.

En España, la institución que ha simbolizado la presencia cultural de Estados Unidos en la primera década de la España franquista fue la Casa Americana. Todas sus actividades tenían como finalidad coordinar un conjunto de relaciones públicas en el exterior promovidas por el propio gobierno norteamericano. Sus orígenes se remontan a la instalación de la representación de la Office of War Information en España. Su sede estaba situada en Madrid, en la calle de Ramón de la Cruz ${ }^{\circ}$ 5, y sus actividades se centraban en la publicación de unos boletines de noticias, documentales, emisiones de radio y prensa, sufriendo las vicisitudes propias de una agencia de información en tiempos de guerra. Un aspecto cultural importante fue el hecho de que se abriera al público una biblioteca, en el mes de enero de 1943. Las personas encargadas de la misma fueron Frances Foltz ${ }^{19}$ y su ayudante Helen Liendres. En 1943 la biblioteca contaba con 695 libros en continua circulación. En un principio, los visitantes mostraban especial interés en consultar los boletines de noticias y otras informaciones sobre la implicación bélica de los Estados Unidos.

En 1945, al finalizar la conflagración mundial, el Congreso estadounidense cortó drásticamente los fondos destinados al desarrollo de las campañas propagandísticas y culturales en el exterior debido a la gran influencia de la tradición liberal norteamericana, contraria a cualquier intervención oficial en la formación de la opinión pública, ya fuera nacional o internacional. Éste sería el origen de algunos de los vaivenes propios de la acción cultural estadounidense en el exterior y, por supuesto,

16 En la obra de WinKLER, 1978, se estudia con detalle la labor de la Office of War Information en el período comprendido entre los años 1942-1945.

17 Hughes, Emmet John (1920-1982). Trabajaba en la Universidad de Columbia con Carlton J. H. Hayes cuando éste fue nombrado embajador en Madrid y al que acompañó como Agregado de Prensa de la embajada estadounidense. Después de su llegada a Madrid, Hughes se incorporó al ejército del norte de África. Allí se integró en la "Office of Strategic Services". Poco después volvió a Madrid y asumió de nuevo, "al menos ante la autoridades españolas" su cargo de Agregado de Prensa de la embajada estadounidense, siendo el jefe del "Outpost" de la "Office of War Information", encargándose de todo lo que estuviera relacionado con temas de propaganda e información durante los cuatro años que estuvo destinado en España (1942-1945). Hughes ofrece en su libro Report from Spain unos detalles muy reveladores sobre la evolución del aparato de propaganda del franquismo, desde su inicial belicosidad hasta la vidriosa neutralidad posterior a 1943.

18 HugHES, 1947, p. 191, describe abiertamente las actividades que realizaba en la representación diplomática estadounidense en Madrid: "The last of the four years of my official mission in Spain, while I continued to edit the output of informational and propaganda material, was primarily dedicated to work of another sort: political intelligence".

19 Frances Foltz era la esposa de Charles S. Foltz Jr., corresponsal de la agencia de prensa Associated Press en España. Charles S. FoLTZ, JR. era el autor de la obra sobre España The Masquerade in Spain. A Report Unmasking the Rulers of Modern Spain. 
también en España ${ }^{20}$. Uno de los cambios que se registran en la Casa Americana se produce en el mes de agosto de 1945, cuando se incorpora a la misma Lesley Frost, hija del poeta Robert Frost. Bajo su dirección, la biblioteca pasó a tener 3.500 libros y el servicio de préstamo tuvo una circulación diaria de 150 libros y revistas, siendo los más solicitados los que abordaban temas económicos y técnicos. El récord de visitas ascendió a las 800 diarias. En la prensa estadounidense se reflejaba la labor cultural que realizaba la institución americana en España:

El esfuerzo americano, representado por la Casa Americana (American House) ha dejado una huella importante en la vida cultural española, debido a la energía de los Americanos que están al frente de la misma ${ }^{21}$.

Paralelamente, durante los primeros años de posguerra, se seguían realizando en la Casa Americana unas tareas de información que eran fundamentales para el Departamento de Estado estadounidense. No obstante, las acciones encomendadas a esta institución eran básicamente la biblioteca y el servicio de préstamo de libros; la divulgación o "propaganda" de los diferentes productos culturales estadouniden$\operatorname{ses}^{22}$, la difusión de la enseñanza del idioma inglés y la colaboración con las instituciones socioculturales españolas. A continuación transcribimos cómo se presentaban al lector norteamericano algunas de las actividades que realizaba la Casa Americana en Madrid. Hay que mencionar que en este testimonio se destaca el altruismo de las acciones culturales estadounidense en España, que en realidad se contradecía con las verdaderas intenciones del gobierno norteamericano, interesado en preparar el terreno para llegar a un acercamiento entre ambos países:

Algunas de las miles de personas que usan sus bibliotecas y salas de lectura y ven sus películas y algunos de los cientos de miles que escuchan sus emisiones de radio sólo la ven como una oportunidad de aprender algo sobre los Estados Unidos. Y como el interés por los Estados Unidos, por sus costumbres y por sus formas de vida es muy grande, la mayoría de los españoles quiere conocer antes o después lo que son los Estados Unidos y qué representan [...] Además de las salas de lectura y bibliotecas, la Casa publica un boletín de noticias americanas en español [...] Si los Estados Unidos tienen una segunda intención, eso está bien oculto. En apariencia, desea solo mostrar lo que significa la libertad ${ }^{23}$.

20 Los cambios en la diplomacia pública norteamericana durante los primeros años de la Guerra Fría son analizados en: NinKovich, 1981; Hixon, 1997; Osgood, 2006; Cull, 2008 y Pizarroso QUINTERO, 2009.

21 Dosch-Fleurot, Arno: "U. S. Boots Cultural relations in Spain”, Christian Science Monitor, Boston, 10-VII-1947.

22 Las tareas de propaganda que llevaba a cabo la Casa Americana quedan reflejadas en la prensa norteamericana: "Here in the library of the Madrid Casa Americana-American House-many Spaniards come daily to learn more about the United States. It is one of the channels through which the United States Information Service reaches present and potential friends of America", en Editorial, "Bit of America in Spain”, Christian Science Monitor, Boston, 11-X-1949.

23 Editorial, "America opens it's famed Casa for Spaniards", Christian Science Monitor, Boston, 11-X-1949. En este artículo se observa una mirada benevolente sobre las actividades de la Casa Americana en Madrid. 
La Casa Americana también impulsó otras actividades, entre las que se incluían recepciones y proyección de películas, por medio de las cuales se trataba de atraer a ciertos sectores de la sociedad española, especialmente a aquellos relacionados con la actividad económica y con las instituciones eclesiásticas. En la prensa estadounidense se describe de forma idílica lo que representaba la Casa Americana en la sociedad española y el público que la frecuentaba, en el que estaban presentes todos los sectores de la misma. Se afirma que se había convertido en una institución popular americana en España, que era frecuentada por "todo tipo de españoles, desde el Duque de Alba pasando por los trabajadores de cuello blanco hasta los trabajadores manuales ${ }^{24}$.

La Office of War Information (OWI) registró un florecimiento de las actividades que desarrollaba, sin embargo, debido, principalmente, al recorte que se introdujo en los presupuestos estadounidenses una vez finalizada la Segunda Guerra mundial, este organismo dejó de funcionar oficialmente a finales del verano de 1945, incorporándose sus funciones en la Office of International Information and Cultural Affairs, dependiente a su vez del Departamento de Estado. Dentro de este plan de ajuste presupuestario, en julio de 1947 se clausuró la Casa Americana y su biblioteca se trasladó temporalmente al edificio de la Embajada, donde se habilita una pequeña sala de lectura para la consulta de sus fondos.

Aunque no fue hasta 1948, fecha en la que ya estaba bastante claro que el escenario internacional quedaba abocado a un enfrentamiento entre bloques, que el Congreso norteamericano proveyó los fondos económicos necesarios para desarrollar un plan estable y continuado de diplomacia pública, que se fue ampliando progresivamente. En esos momentos, la campaña propagandística de los Estados Unidos en España tenía el claro objetivo de crear un marco adecuado para la futura inclusión del país dentro de la cobertura militar de contención de la Unión Soviética. Es en 1948 cuando la Casa Americana reabre de nuevo sus puertas en la calle de Marqués del Riscal, donde permanecerá hasta 195725 , para luego ubicarse en el madrileño Paseo de la Castellana. Las Casas Americanas de Madrid y Barcelona (1949) trataban de "popularizar a los Estados Unidos entre la población española" para obtener un claro fin político:

[...] asegurar una actitud suficientemente amistosa por parte del gobierno español para llegar a tener una plena cooperación en el caso de una posible guerra ${ }^{26}$.

Esta labor se siguió desarrollando en las nuevas sedes de la Casa Americana que se inauguraron, en años sucesivos, en ciudades como Bilbao (1950), Sevilla (1951) y Valencia (1952). Posteriormente, tras la firma de los acuerdos militares de 1953, se

24 Ibidem.

25 "El cambio de sede se recoge en la prensa estadounidense: Editorial, "Thomas Driver, who is the representative of USIS in Spain, began by taking the whole floor of a large building in Madrid Calle Marques de Rescal [Riscal] for the Casa there", en "America opens its famed Casa for Spaniards", Christian Science Monitor, Boston, 11-X-1949.

26 Cit. en Delgado Gómez-Escalonilla, 2009a, p. 113. 
abrieron centros en Cádiz (1955) y Zaragoza (1955), ambas ciudades cercanas a las nuevas bases militares estadounidenses ${ }^{27}$.

En la Casa Americana se organizaban exposiciones que fueron cambiando en los primeros años de la década de los 50, desde temas que interesaban a amplios sectores de la población hasta la especialización en temas culturales específicos, como la literaria, la pintura ó la arquitectura. Asimismo, se pasa, en un breve espacio de tiempo, de una política de puertas abiertas a otra en la que se limitaba el acceso a las actividades mediante invitación expresa.

Sin embargo, lo que sí simbolizaría ostentosamente a EE.UU. como gran potencia sería la edificación de la nueva sede de la embajada en el céntrico Paseo de la Castellana. Cuando el New York Times del 10 de septiembre de 1951 informaba que el nuevo edificio comenzaría a construirse dentro de un mes, tras la demolición del palacete "La Huerta", en su día residencia de José Canalejas, nadie podía sospechar que iba a ser objeto de controversias.

La finalización de las obras estaba prevista al cabo de dieciocho meses. El edificio, de grandes dimensiones, sería de hormigón recubierto de piedra blanca, mientras que dos de sus fachadas quedarían totalmente acristaladas con marcos de aluminio. El nuevo edificio, de estilo funcional estadounidense, rectangular, con siete pisos, ofrecía una notoria semejanza con el de la ONU en Nueva York. La edificación estaba destinada a albergar todas las oficinas de la embajada, así como la residencia del embajador en una de las alas, con entrada propia desde el Paseo de la Castellana.

Un mes más tarde, el New York Times inserta un artículo donde informa que las quejas que la construcción había suscitado en la prensa española y entre muchos madrileños estaban remitiendo. Algunos consideraban a la edificación "demasiado moderna" y no acorde con el entorno arquitectónico. Otros opinaban que proyectaría su silueta "horriblemente paralelepípeda" sobre el "melancólico" Paseo de la Castellana. También se afirmaba que el Ayuntamiento de Madrid jamás había visto el proyecto y, por tanto, tampoco había concedido la licencia de obra. Tras estas quejas, polémicas en la prensa y otras muestras de desagrado, una reunión entre los responsables de la obra y las autoridades municipales acalló las críticas al asegurarse que los árboles conservados en el patio de la futura embajada no harían visible al nuevo edificio desde el Paseo de la Castellana. Las críticas más ácidas aparecieron en las páginas del diario falangista Arriba, pero luego fueron reproducidas, en tono más comedido, en otros periódicos madrileños.

La preocupación del New York Times, en cambio, se centraba en lo costosas que venían siendo para los contribuyentes estadounidenses la construcción de obras "faraónicas" para ubicar las representaciones de EE.UU. en diversos países. El periódico se quejaba también de la innecesaria cantidad de personal adscrito a la embajada madrileña ${ }^{28}$. Sin embargo el Evening Star afirmaba que el coste del nuevo edifi-

27 Las Casas Americanas que se abrieron en España tuvieron los períodos de actividad que se presentan a continuación: Madrid (1942-1947 y 1948-1968); Barcelona (1949-1968); Bilbao (1950-1961); Sevilla (1951-1965); Valencia (1952-1957). Zaragoza (1955-1957) y Cádiz (1955-1957). Sobre este tema se puede consultar la obra de LEÓn AguinagA, 2009, p. 153.

28 New York Times, New York, 14-X-1951. 
cio, que ascendía a 750.000 dólares, se había financiado con unas sumas de dinero obtenidas con la liquidación de los bienes alemanes que quedaban en España a través del programa de reparaciones ${ }^{29}$.

\section{INTERCAMBIOS CULTURALES}

Durante el transcurso de la Segunda Guerra mundial se generalizó en las embajadas estadounidenses de diferentes países la figura del Cultural Affair Officer (CAO), al mismo tiempo que se desarrollaban los organismos para la promoción cultural ${ }^{30}$. En 1943 se nombró al profesor John Van Horne ${ }^{31}$ para desempeñar las funciones de Agregado Cultural en Madrid, siendo la persona encargada de coordinar las tareas culturales de la embajada y promover el intercambio entre los dos países. Asimismo, Van Horne participó activamente en la difusión de la cultura estadounidense en España, pronunciando conferencias en la sede de la Casa Americana ${ }^{32}$ y en instituciones españolas sobre diferentes aspectos sociales y culturales de los Estados Unidos $^{33}$.

Paralelamente, en los años de la posguerra se inicia un relanzamiento de la diplomacia cultural española. La política exterior del franquismo era una mezcla de acción

29 "[State Department] Officials said the property was purchased with blocked Spanish currency which came to the United States as part of the share under the reparations program from liquidation of German external assets in Spain. These funds, officials pointed out, could not be converted into dollars. They said it was part of a general American policy to build up assets in the form of real property abroad from such funds acquired in reparations settlements", en Editorial, "U. S. uses proceeds of reparations to buy Madrid Embassy site", Evening Star, Washington, D. C., 23-III-1949.

30 ARNDT, 2005, p. 88 recoge la siguiente observación: "Noteworthy academic figures immediately showed up on OSS and OWI payrolls around the World with the title of PAO or CAO".

31 John Van HoRnE (1889-1959), profesor de lenguas romances en la universidad de Iowa (19141916) y de la de Illinois desde 1917 hasta su retiro en 1957. Su principal interés era la literatura hispana. Viajó por Europa, el Caribe, Chile, Argentina y Perú. Desde 1943 hasta 1946 desempeñó el puesto de agregado de cultura en España, siendo el encargado del intercambio de información cultural (educativa, literaria, artística y teatral). En 1944 y 1945 impartió clases en los cursos de verano de la Escuela de Estudios Hispanoamericanos de Sevilla. Para obtener una información más de tallada de su labor véase, Pietrangeli, 1960, pp. 174-175.

32 Este acto se reflejó en la prensa española: “Ayer a las siete y media de la tarde se inauguró, una serie de conferencias en la Casa Americana sobre varios aspectos de la cultura norteamericana. El embajador Mr. Norman Armour, pronunció unas palabras a modo de introducción para explicar el propósito de la serie. La primera conferencia fue pronunciada por el Agregado Cultural de la embajada John Van Horne, Versó sobre literatura reciente de los Estados Unidos, señalando como rasgos generales la íntima relación con movimientos sociales, el creciente cosmopolitismo y sátira, una constante democratización y extensión de las letras a todos los sectores de la sociedad", en Editorial, "En la Casa Americana. Ciclo de Conferencias sobre Cultura Estadounidense", $A B C$, Madrid, 1-XI-1945, p. 14.

33 La embajada española en Washington incluye en su boletín informativo algunas de las actividades culturales del Agregado Cultural norteamericano en Madrid: "Dr. John Van Horne, former Cultural Attaché of the U. S. Embassy in Madrid, delivered a lecture at the Institution of the Divine Master, Madrid, on January 17, 1946, on the subject: "Primary Education in the United States" en Editorial, "Spain's Program of International Cultural Relations. Recent Exchanges of Specialists in the Arts, Sciences and Humanities". Spain. Information Bulletin Published by the Spanish Embassy, Washington, D. C. Special Edition, Vol. 1/8, 28-IX-1946, p. 3. 
cultural y propaganda para proyectar una imagen positiva del país que le permitiera ir tendiendo lazos de unión con los Estados Unidos y Gran Bretaña, de lo que deja constancia Emmet J. Hughes en su libro Report from Spain ${ }^{34}$. Tal política iba dirigida a aquellos sectores que mostraban un cierto interés por el rico patrimonio histórico, artístico e intelectual de España, o que eran potencialmente afines a sus posturas ideológicas aunque rechazaran su sistema de gobierno.

Sin embargo, en general, se puede afirmar que durante la etapa que cubre este estudio el régimen franquista mostró un cierto rechazo hacia los Estados Unidos, al tiempo que el país vivía una etapa de aislamiento. Pero hay que matizar que este distanciamiento extremo sólo se tuvo lugar hasta 1948, y que a partir de entonces la política estadounidense con respecto a España fue cambiando de forma paulatina. Como consecuencia de ese distanciamiento España no fue incluida en el Fulbright Program $^{35}$ y sólo se benefició de algunas acciones del International Information and Educational Exchange Program. Esta situación se prolongaría en el tiempo debido a que:

La hostilidad del gobierno español también entorpecía la reanudación de las relaciones culturales. El intercambio de profesores y estudiantes estaba suspendido [...] Al ejecutivo norteamericano le contrariaban aquellos impedimentos, pero España quedaba todavía lejos de su campo de prioridades. Hasta su incorporación militar al sistema de defensa occidental no comenzaron a tomarse medidas efectivas al respecto ${ }^{36}$.

La imagen cultural de la España franquista en los Estados Unidos no era por entonces precisamente benévola. Charles Foltz señala, por ejemplo, que la Biblioteca Nacional clasificaba los libros por grosor; que "la Familia" [la oligarquía] que en tiempos pasados fomentó la literatura ya no lo hace; que los grandes escritores y artistas o han fallecido o se encuentran en el exilio; que no hay nuevos escritores o artistas que les hayan reemplazado; que una indiscreción de Jacinto Benavente hizo que durante dos años estuviera censurado; que Pio Baroja escribió poco tras la Guerra Civil y lo poco que escribió fue acallado por la censura; que Azorín, a pesar de colaborar con la prensa falangista, nunca llegó a alcanzar su anterior brillantez; que el muralista José María Sert viajaba entre sus estudios de Paris y Barcelona; que

34 HugHES, 1947, p. 129. "Since the end of World War II, the propaganda machine of the Spanish government has found itself viewing the United States in a light very different from that which seemed to cast such dark shadows two or three years ago. In those years when the gods of war smiled so seductively upon the Axis powers, all the resources of the Falange were mobilized to translate into Spanish, the directives of Dr. Goebbels - with special emphasis on the theme of the "decadent democracies" of the west. But since the wave of the future has become the backwash of yesterday, the propaganda appeal of the Spanish regime [...] has anxiously sought to demonstrate that the mutual friendship links with the United States and Great Britain".

35 El Fulbright Program fue creado en 1946 con la aprobación de la Fulbright Act y reformado en 1961 con la Fulbright-Hays Act. Su principal objetivo era difundir una imagen "full and fair" de la sociedad estadounidense, tratando de contrarrestar las visiones distorsionadas que existían sobre la misma en el exterior. La creación y desarrollo del Programa Fulbright se analiza en la obra de JOHNSON - Colligan, 1965. El Programa Fulbright en España es estudiado con detalle por Delgado GómezESCALONILLA, 2009b.

36 Delgado Gómez-Escalonilla, 2009a, p. 107. 
el escultor Mariano Benlliure ya octogenario apenas producía algo; que Ignacio Zuloaga antes de morir se enriqueció con encargos estatales, incluido un retrato de Franco. Pero todos estos escritores y artistas pertenecían al pasado... Para Foltz, las razones del estancamiento cultural tienen mucho que ver con la opinión que las artes y la educación merecían a la oligarquía española. Así, la revista El Español afirmaba que Cervantes "no era una gran autor sino un loco", al tiempo que el general Millán Astray espetó en 1939 un “¡Muerte a la inteligencia!”. Pero, a juicio de Foltz, quien mejor simbolizaba la visión que la oligarquía tenía de la educación era el Marqués de Lozoya, Director General de Bellas Artes del Ministerio de Educación, catedrático de la Universidad de Valencia, miembro de la Academia de Bellas Artes e Historia y miembro del Consejo de la Hispanidad, cuando escribió en la prensa "oligárquica" el 3 de febrero de 1938 lo que sigue:

Todos los infortunios de España provienen del estúpido deseo de los gobiernos de enseñar a los españoles a leer. Enseñar a una persona a leer es obligarle a asumir una posición que no hará sino crear infortunio a la persona misma y a la Patria.

Y Foltz concluye: "tal es el veneno que corroe el alma de España 37.

\section{INICIATIVAS CULTURALES NORTEAMERICANAS Y ESPAÑOLAS}

A pesar de que España no estaba incorporada plenamente en el International Information and Educational Exchange Program, existieron algunas iniciativas oficiales que facilitaron las relaciones culturales con la España franquista ${ }^{38}$. Una de ellas fue la acción que coordinaba el Institute of University Studies Abroad, que facilitaba asesoramiento y ayuda a los estudiantes universitarios norteamericanos que iban a realizar algún curso en universidades extranjeras, entre ellas las españolas. El Institute se encargaba de contactar con las universidades a las que iban y les tramitaba la documentación necesaria para poder realizar la inscripción en dichos cursos. Estos estudiantes siempre se desplazaban en grupos. Esta iniciativa tuvo una gran difusión en la prensa de los Estados Unidos ${ }^{39}$.

Otra iniciativa oficial para promover el intercambio de estudiantes fue la que se materializaría en 1951, cuando el Bureau of Adult Education del New York State Department of Education, conjuntamente con el Experiment in International Living, desarrollaron una acción que era conocida como el "Ambassador Project." En esta experiencia participaron sólo cuatro estados de la costa este norteamericana: Nueva York, Michigan, Vermont y Connecticut. Este proyecto enviaba a jóvenes estadounidenses de estos estados como "embajadores" a varias naciones europeas y sudamericanas, estando España incluida entre ellas. El objetivo fundamental era que a través de los jóvenes que participaban en el proyecto se fomentara el mutuo conocimiento y un mejor entendimiento entre Estados Unidos y el país que los acogía. Esos jóvenes representaban a diversas comunidades norteamericanas de esos

${ }^{37}$ FoLTZ, 1948, pp. 274-275.

38 Para estudiar la política cultural norteamericana consultar los diferentes artículos que versan sobre este tema en NiÑo RODRÍGUEZ, 2009.

39 Editorial, "European universities set sessions", The Southern Cross, San Diego, 1-II-1951. 
cuatro estados y su financiación corría a cargo de la comunidad en la que vivían, como recoge New York Times ${ }^{40}$.

Estos jóvenes "embajadores" no viajaban como turistas, sino como personas que se integraban en unas familias de acogida en los sitios que visitaban. La estancia era de dos meses y en ese tiempo llegaban a integrarse en la familia y a formar parte de esa comunidad. Los promotores de esta experiencia aseguran que el Ambassador Project

[...] es un ejemplo vivo de cómo la juventud de este país puede cooperar con las gentes de otros países para trabajar a favor de un mejor entendimiento ${ }^{41}$.

Junto a esas iniciativas institucionales o comunitarias encontramos unas acciones individuales para fomentar los intercambios culturales entre los ciudadanos de Estados Unidos y España. Una de ellas es la promovida por Angier Biddle Duke, ayudante del embajador estadounidense en España, Stanton Griffit. Duke anunció la creación de la "Beca Duke" por la cual un estudiante de habla española, incluidos los países de Sudamérica, podría estudiar en la Duke University, situada en la localidad de Durham en el estado de Carolina del Norte. La ayuda incluía el viaje y la estancia. El propio patrocinador asegura que "la beca tiene como finalidad que los estudiantes extranjeros adquieran un mejor conocimiento de los Estados Unidos". Esta iniciativa fue difundida en la prensa norteamericana ${ }^{42}$.

Asimismo, algunas instituciones privadas estadounidenses de prestigio, cuyos recursos también eran privados, fomentaron las relaciones culturales entre ambos países a través de su apoyo financiero a programas de intercambio de estudiantes. Una de ellas fue la Carnegie Foundation de New York, fundada por Andrew Carnegie en 1911 para promover el avance y la difusión del conocimiento y el entendimiento entre los pueblos, siendo una de las más antiguas e influyentes fundaciones norteamericanas. Una de sus acciones más conocidas era la concesión de becas a estudiantes de español del Middlebury College en Vermont, para cursar estudios en la universidad madrileña. Con esta iniciativa se pretendía favorecer los intercambios de estudiantes con la intención de "indirectamente mejorar el entendimiento entre España y los Estados Unidos"43. Es necesario mencionar que en la Escuela Española del Middlebury College impartían docencia en los cursos de verano varios intelectuales españoles exiliados en Estados Unidos que ejercían como profesores en distintas universidades estadounidenses, siendo prácticamente nulas las relaciones de todos ellos con la España de Franco.

Otra institución de carácter privado que propició vínculos culturales entre Estados Unidos y España fue la Fundación del Amo. Gregorio del Amo, médico,

40 "The young people participating in the program believe that peace can come only if people understand one another. They are convinced that understanding comes when people assemble informally as friends and neighbors", en B. F. "Young 'Ambassadors' Going Abroad", New York Times, New York, 17-VI-1951.

41 Ibidem.

42 Editorial, "Duke gives scholarship. Envoy in Spain would allow foreigners to study here", New York Times, New York, 18-II-1951.

43 Editorial, "Study in Spain planned. Madrid University favors visit by U. S. college group", New York Times, New York, 1-VI-1950. 
diplomático y filántropo español nacionalizado estadounidense, creó la "Del Amo Foundation" el 14 de mayo de 1929, con el propósito de estrechar los lazos y las relaciones culturales entre España y el estado de California. Pronto empezó a ejercer el mecenazgo en beneficio de la Universidad de California, la Universidad del Sur de California y la Universidad Central de Madrid ${ }^{44}$. Una de sus iniciativas más difundidas fueron las becas concedidas a estudiantes californianos para cursar estudios en la universidad madrileña ${ }^{45}$, permitiéndoles conocer directamente la cultura española como se refleja en estas líneas del N. Y. Journal American:

Ellos simplemente radiaban entusiasmo, cuando nos contaban sobre sus estudios, sus fines de semana, que pasaban visitando las catedrales, museos, castillos y otros restos históricos de España. Cuando estos estudiantes vuelven a sus casas, ellos ejercerán como embajadores de buena voluntad de España e incluso incrementan el prestigio de América en España ${ }^{46}$.

La Hispanic Society of America, fundada en 1904 por el filántropo hispanista Archer M. Huntington, fue otro foco de difusión de la cultura española en los Estados Unidos. Su sede se encuentra en la ciudad de Nueva York y en ella se organizaban actividades para promover el conocimiento de la cultura española entre los norteamericanos. Con el paso del tiempo fue reuniendo una gran colección de libros, objetos y obras de arte españolas. El propio Huntington resume en estas palabras su principal finalidad:

[...] yo quiero conocer España como es y dejarla reflejada en un museo [...] Si consigo escribir un poema con ese museo, será fácil de leer ${ }^{47}$.

Por su parte, en las universidades norteamericanas, los departamentos de español se multiplicaban y tenían una gran afluencia de estudiantes. Muchos de ellos estaban liderados por republicanos españoles exiliados, registrándose una condena hacia el régimen franquista y a su cultura oficial en la mayoría de estas universidades. Sin embargo, también contribuyeron a profundizar el conocimiento mutuo entre los dos países favoreciendo el intercambio de estudiantes. Entre las actividades que ofrecían a sus alumnos había unos cursos que se realizaban en diferentes países europeos, entre ellos España. Dentro de los "Foreign Summer Workshops", la New York

44 En este artículo queda constancia de los estrechos lazos que se habían establecido entre la Fundación del Amo y la Universidad de Madrid: "Thanks to the remarkable foresight and bounteous magnanimity of the late Dr. Gregorio del Amo of Los Angeles, the University of Madrid has become instrumental in fostering friendly and cultural relations between Spain and the United States", en Sepulveda Pignatelli, Conchita (Princess), "New spirit of cultural relations rises at modern University in Spain", N. Y. Journal American, 14-VIII-1948.

45 Estas líneas están escritas por una mujer que viaja a Madrid acompañando a su hija que viene a estudiar a España: "We were again surprised to find so many American students about the campus... And of course we were delighted to meet the Del Amo scholarship students from Southern California". Ibídem.

46 Ibidem.

47 Editorial, "Hispanic Foundation birthday”, Evening Star, Washington, D. C., 1-VIII-1949. 
University School of Education programó, en el verano de 1950, su primer seminario sobre vida y cultura española. Durante seis semanas algunos de sus estudiantes participaron en un curso de verano que se realizó en España y que incluía la lengua, la literatura y la cultura del país. Igualmente, formaban parte del programa varias visitas a diferentes ciudades, a otras provincias y a diversas manifestaciones culturales ${ }^{48}$.

Una acción de gran impacto académico y cultural, aunque menos frecuente debido, principalmente, a su elevado coste, consistía en el hecho de que universidades estadounidenses acogieran en sus aulas a estudiantes españoles. En 1951, un grupo de 16 alumnos procedentes de todo el mundo participaron en el Foreign Student Summer Project en el Massachussets Institute of Technology (MIT). Uno de ellos fue el español José Mendiluche ${ }^{49}$ como se recoge de forma escueta en la prensa coetánea estadounidense.

Simultáneamente, durante el período que comprende esta investigación, España también trató de acercar su cultura a los ciudadanos estadounidenses a través de diferentes acciones. Así, en 1948, el Instituto de Cultura Hispánica promovió el primer curso de verano que se realizó en la Universidad de Madrid una vez finalizada la Segunda Guerra mundial, que estuvo dirigido tanto a profesores como a estudiantes norteamericanos. En la organización del mismo participó el Consejo Superior de Investigaciones Científicas con la colaboración del Spanish Student Tours y del Institute of University Studies Abroad. Los estudiantes se costeaban el viaje y la estancia, y en los cursos se incluían clases de lengua, literatura, arte e historia española. También se realizaban visitas culturales a ciudades históricas, así como a diversos monumentos. También se incluía una excursión por Andalucía. Durante el primer curso, el director fue Manuel Fraga Iribarne ${ }^{50}$. Entre las treinta y nueve personas que integraron este primer grupo se encontraban el Rvdo. P. Joseph Manrique, de la Fordham University, y Benjamín Hoffman, presidente de la Philadelphia Geographic Society ${ }^{51}$.

Una de las actividades académicas que tuvo mayor aceptación y difusión en Norteamérica era la que ofrecían las universidades españolas a través de los cursos de verano que se realizaban en sus campus. En general, estaban dirigidos a jóvenes estudiantes extranjeros, entre ellos los norteamericanos. En ellos se trataba de impulsar la enseñanza de la lengua española y de dar a conocer la cultura, el arte y las costumbres. Por lo general, solían incluir visitas a diferentes localidades de la geografía española. Una de las universidades españolas más conocidas en Norteamérica por realizar este tipo de actividades era la de Madrid $^{52}$, siendo también una de las más

48 Editorial, "NYU School of Education sets foreign summer workshops", Christian Science Monitor, Boston, 22-IV-1950.

49 Editorial, "From many lands -a study group at MIT", Christian Science Monitor, Boston, 9-VI-1951.

50 Para conocer más detalles sobre estos cursos consultar el artículo de Delgado GómeZESCALONILLA, 2009a, p. 53.

51 Editorial, "39 Americans return from studying in Spain”, Evening Star, Washington, D.C., 6-IX1948. Asimismo, formaba parte de este grupo el español afincado en los Estados Unidos Rvdo. P. José Antonio Sobrino, S. J., quien escribiría unos años más tarde algunas reflexiones sobre Estados Unidos que aluden a muchos de los tópicos que los españoles del momento albergaban respecto a aquel país. Véase, SOBRINO, 1952.

52 Editorial, "Study in Spain planned. Madrid University favors visit by U. S. college group", New York Times, New York, 1-VI-1950; "European universities set sessions", The Southern Cross, San Diego, 1-II-1951. 
reconocidas por sus modélicas instalaciones con "edificios modernos y estudios bien planificados en todos sus detalles". También lo era por su biblioteca y sus investigadores $^{53}$. Los grupos de profesores y estudiantes que venían a estos cursos tenían una acogida favorable e, incluso, en el verano de 1948, el propio Franco les llegó a recibir en su residencia de El Pardo ${ }^{54}$.

Por su parte, el gobierno de Franco reconoció oficialmente las tareas realizadas por personalidades de diferentes sectores de la sociedad estadounidense en favor de España. Entre ellas cabe destacar la concesión de la Cruz de Alfonso X el Sabio, en enero de 1951, al Rvdo. Joseph F. Thorning, editor de World Affairs y pastor de St. Joseph's Catholic Church, Carrollton Manor, Maryland. El régimen de Franco agradecía la gran ayuda prestada por Thorning en favor del Movimiento Nacional y del restablecimiento de las relaciones diplomáticas, culturales y económicas entre Washington y Madrid. Thorning había escrito numerosos artículos sobre España y Sudamérica que habían sido publicados en el diario Washington Post a finales de los años $30^{55}$.

Entre las figuras del mundo académico norteamericano galardonadas por las instituciones españolas cabe destacar al doctor Selman A. Waksman, microbiólogo del Rutgers College of Agriculture, a quien se le concedió el título honorífico de Doctor Honoris Causa por la Universidad de Madrid, en una ceremonia que se celebró ante un gran auditorio 56 .

También tuvo una gran difusión en la prensa norteamericana la visita que realizó a España el filósofo jesuita norteamericano Rvdo. Hunter Guthrie, decano de la Graduate School de la Georgetown University, para asistir a los actos conmemorativos de los filósofos españoles Francisco Suárez y Jaime Luciano Balmes. Simultáneamente, durante su estancia en España asistió a reuniones académicas en Madrid y Barcelona ${ }^{57}$.

Asimismo, en la prensa norteamericana se recogen las actividades que realizaban en Estados Unidos algunas figuras representativas de la vida intelectual española. Entre ellas podemos destacar al filósofo José Ortega y Gasset, quien intervino activamente en el bicentenario de Goethe celebrado en la ciudad de Aspen, Colorado, participando en calidad de "golden talker" junto a Robert M. Hutchins y Clifton

53 "We were gratified to find that most of the buildings are very modern and well planned in every detail $[\ldots]$ We were again surprised to find so many American students about the campus. As a matter of fact, we heard so much English conversation that at times we had the impression that we were visiting an American institution. And of course we were delighted to meet the Del Amo scholarship students from Southern California". En Sepulveda Pignatelli, Conchita (Princess), "New spirit of cultural relations rises at modern University in Spain", N. Y. Journal American, New York, 14-VIII-1948.

54 Editorial, "96 Americans study in Spain meet Franco", Chicago Daily Tribune, Chicago, 10VIII-1948.

55 Editorial, "Rev. Thorning receives Colombian condecoration”, Evening Star, Washington, D.C., 16-IV1951; "Father Thorning awarded Cross by Colombia", Washington Post, Washington, 16-IV-1951.

56 Editorial, "Madrid honors Rutgers aids", New York Times, New York, 22-IV-1950; "Dr. Waksman wins acclaim in Europe", New York Times, New York, 13-VIII-1950.

57 Editorial, "Dean of graduate school returns from Spain", Evening Start, Washington, D.C., 18XI-1948. 
Fadiman ${ }^{58}$. También hay abundantes comentarios sobre su obra La rebelión de las masas en los diarios norteamericanos ${ }^{59}$. Otra de las personalidades del mundo académico español que aparecía frecuentemente en los periódicos norteamericanos fue el médico, historiador, escritor y pensador español Gregorio Marañón y Posadillo. Sus aportaciones a la medicina fueron difundidas ampliamente en la prensa estadounidense coetánea 60 .

Simultáneamente, la prensa católica norteamericana publicaba algunos artículos en los que se anunciaba un "renacimiento intelectual en España", especialmente en sus universidades y en sus ambientes académicos y culturales, tratando de ofrecer al ciudadano estadounidense una visión de la España de Franco más moderna y dinámica. Uno de los artículos más significativos está fechado a finales de 1947 y en el se presenta una idea de España muy positiva, tratando de favorecer un acercamiento con los Estados Unidos:

Una de las evidencias más significativas de la vitalidad de la vida intelectual de España es la transformación que está teniendo lugar en las universidades. La universidad española, especialmente durante la última centuria y parte de la presente, ha llegado a estar momificada en un grado alarmante [...] Esto ha cambiado sustancialmente después del final de la guerra civil. El Estado ha sido generoso al incrementar la dotación económica de las universidades [...] Al visitar estas instituciones en Salamanca, Oviedo, Valladolid, Murcia, Barcelona, Valencia y Madrid, me quedé impresionado por la "moderna" actitud de estudiantes y profesores ${ }^{61}$.

También hay que mencionar al Instituto Internacional, cuya sede estaba en Boston, y que desde que fue fundado por la Señora Alice Gulick en Madrid en 1903, estuvo muy vinculado a las iniciativas educativas de la Institución Libre de Enseñanza. El Instituto Internacional constituyó un eje fundamental sobre el que se articularon las relaciones entre las instituciones educativas estadounidenses y espa-

58 Editorial, "Report on Spanish scholars", New York Times, New York, 26-II-1949; "Goethe Fete split into two sections. 20-day festival at Aspen, Col., starts June 27 and includes panels by noted scholars", New York Times, New York, 19-IV-1949. SteVEns, Austin, "New life pattern is seen for Europe. Jose Ortega y Gasset asserts at Bicentennial of Goethe continent revises tenets", New York Times, New York, 3-VII-1949. SPRAGUE, Marshall, "Promoters of Colorado Festival Planning to lighten schedule in future", New York Times, New York, 6-VIII-1950.

59 También eran recogidas en la prensa estadounidense coetánea unas reseñas elogiando el libro de José Ortega y Gasset, La rebelión de las masas. Ortega fue colaborador del diario El Sol desde 1917, donde publica bajo la forma de folletines dos obras importantes: La rebelión de las masas y España invertebrada, en SteIger, Henry W., "Mediterranean vs. Germanic Thought", Christian Science Monitor, 20-X-1949. HendRICK, Kimmis, "More than a book", Christian Science Monitor, 15-V-1951.

60 Editorial, "You should cherish some of your diseases, says M. D.", Times Herald, Washington, D.C., 4-IX-1950. El Dr. Gregorio Marañón y Posadillo (1887-1960). Marañón fue un gran humanista liberal a quien se le considera uno de los más brillantes intelectuales españoles del siglo XX, destacando por su elegante estilo literario. Fue uno de los precursores de la Endocrinología y escribió el primer tratado de Medicina Interna en España y su obra Manual de diagnostico etiológico (1946) fue uno de los libros de medicina más difundido internacionalmente.

61 PAtTEE, Richard, "XII. The intellectual revival in Spain”, The Tablet, 29-XI-1947. 
ñolas. Durante los años de la posguerra fue primero archivo de la embajada de Estados Unidos y después la sede del colegio Estudio y de los programas norteamericanos en Madrid del Middlebury College y de la New York University. El Instituto Internacional no tuvo puntos de contacto con la España franquista, aunque mantuvo una intensa actividad fomentando vínculos entre los estudiantes y profesores españoles y norteamericanos ${ }^{62}$.

En otro orden de cosas cabría resaltar cómo proliferaron tanto en Madrid como en Nueva York las celebraciones relacionadas con Cristóbal Colón y el Descubrimiento de América. Así, para el 12 de octubre de 1951, llegó a Washington Cristóbal Colón de Carvajal y Maroto Pérez del Pulgar, de 26 años, descendiente número 17 del Descubridor. Aparte de ser teniente de la Marina española, Colón de Carvajal ostentaba los siguientes títulos: Almirante y Gobernador de las Indias Occidentales, decimoséptimo Duque de Veragua, quinceavo Duque de la Vega, veinteavo Marqués de Aguilafuente y dieciseisavo Marqués de Jamaica. A su llegada afirmó que "España es muy pro-americana y totalmente anticomunista", al tiempo que auguraba una necesaria intensificación de las relaciones con Estados Unidos. El día 12 depositó junto al embajador de España, José Félix de Lequerica, una corona de flores al pie de la estatua de Cristóbal Colón situada en la Union Station de Washington D.C.63. Previamente, el 20 de agosto, el embajador español asistió en Pittsburgh a la $69^{\mathrm{a}}$ Convención de los Knights of Columbus ${ }^{64}$. De forma simultánea, en Madrid, el embajador de EE.UU., Stanton Griffis, luego de un acto similar, manifestó su agrado por participar en un evento que rememoraba "uno de los muchos lazos que unen a ambos países". Ese mismo día se inauguró en el Museo de Arte Contemporáneo la bienal de arte Hispano-americano, donde, entre otros, participó el neoyorquino Robert Barnett 65 .

\section{LIBROS SOBRE ESPAÑA PUBLICADOS EN ESTADOS UNIDOS, 1945-1952}

El periodo de postguerra y el inmediato inicio de la Guerra Fría, unidos al aislamiento de la España franquista, no conformaron ciertamente un escenario que propiciara la aparición de libros dedicados a la vida cultural española. Tras el enorme repertorio bibliográfico que generó la Guerra Civil española, la mayoría de los títulos posteriores son de carácter político a cargo de diplomáticos estadounidenses acreditados en el país, como las dos obras dedicadas a España del embajador Carlton J.

62 ZuLUETA, 1984, p. 267.

63 Evening Star, Washington, D. C., 11-X- 1951. Foto del acto en New York Times, New York, 13$\mathrm{X}-1951$.

64 Boletín del National Catholic Welfare Conference, 20-VIII-1951. Recoge el discurso íntegro pronunciado por el embajador español. Tras destacar lo que supuso el descubrimiento de América, pasó a destacar la posición de España, su tenaz anticomunismo y su deseo de cooperar con EE.UU. Sus palabras finales aseguraban que "nosotros, los españoles, siempre estaremos al lado de aquellos que deseen mantener encendidas las luces del espíritu en la oscuridad, luces que deben siempre mantenerse vivas para que nuestro mundo no caiga en la barbarie, para que no haya una muerte espiritual”.

65 New York Times, New York, 13-X-1951. 
H. Hayes (1882-1964): Wartime Mission in Spain (1945) y The United States and Spain: An Interpretation (1951). Ambos libros, escritos por un embajador que era además historiador especializado en los nacionalismos europeos, fueron inmediatamente traducidos al español por aportar una visión benevolente del régimen franquista. La última obra citada contiene interesantes observaciones sobre la idiosincrasia española, acompañadas de consideraciones de determinismo geográfico y mezcladas con incursiones históricas para entender la cultura española, todo ello orientado a desechar los prejuicios de los estadounidenses.

Otra obra, en este caso hostil a la España de Franco, fue escrita por Emmet John Hughes (1920-1982) con el título Report from Spain (1947). En ella recapitulaba con perspicacia su experiencia como Agregado de Prensa entre 1942-1946. El público estadounidense también pudo leer el libro del embajador de Gran Bretaña en España entre 1940-1944, Samuel Hoare (1880-1959), Complacent Dictator (1946). La vinculación de Hoare al conservadurismo británico, asumiendo diversas carteras ministeriales y otros altos cargos, confieren a la obra un interés especial, sobre todo para conocer cómo procedió a practicar una política de apaciguamiento con el régimen franquista en plena conflagración mundial, en línea con la orientación de Chamberlain con la que Hoare se sentía plenamente identificado.

Otro estadounidense, Charles Foltz Jr. (1910-2005), periodista y jefe de la oficina de la Associated Press en España durante la Guerra civil y corresponsal durante los primeros años del franquismo hasta su expulsión, publicó The Masquerade in Spain (1948). Como se ha visto, en esta obra el autor arremete contra la oligarquía española, a la que denomina "la Familia", ya que entiende que ésta era la responsable de la existencia de una dictadura. A lo largo de la obra el autor aporta interesantes pinceladas sobre la cultura y la mentalidad de los españoles; resulta particularmente curioso cómo describe el funcionamiento del "enchufismo" para acceder a todo.

No podemos dejar de mencionar el libro de Herbert Feis (1893-1972) The Spanish Story: Franco and the Nations at War (1948). Feis estuvo al frente del Comité Operativo para la Península Ibérica del Departamento de Estado durante el periodo de la Segunda Guerra mundial y, al igual que Charles Foltz, sentía una profunda aversión hacia el régimen franquista. De signo contrario es la obra del hispanista canadiense Richard Pattee -que también desempeño diversas funciones de asesoramiento al Departamento de Estado- This is Spain (1951). Bien documentado, la intencionalidad del libro era desbaratar "la despiadada maquinaria propagandista del comunismo internacional" que, a su juicio, había distorsionado lo que realmente era España. El autor aborda diversos aspectos de la cultura española, tanto en las páginas introductorias como en el capítulo dedicado específicamente a este tema. En esas páginas desecha la extendida idea estadounidense de que la cultura en la España franquista había colapsado amordazada por la represión y la censura. Tal afirmación lleva al autor a hacer una detallada descripción del progreso de la ciencia, la literatura, la poesía, el teatro, las bellas artes, las bibliotecas y librerías, la prensa nacional y extranjera, los distintos niveles educativos, etc. Con frecuencia da la impresión de que el país no vivía bajo un sistema represivo. 


\section{LA INDUSTRIA CINEMATOGRÁFICA ESTADOUNIDENSE EN ESPAÑA}

Desde 1948 aparecen noticias sobre la voluntad de Hollywood de ampliar su producción a Europa. Era lo que se conocía como runaway productions o rodajes patrocinados por Hollywood fuera de Estados Unidos. Por lo que se refiere a España, Alicante se postulaba como el "Nuevo Hollywood", aunque la 20th Century Fox, Paramount y Metro-Goldwyn Mayer tenían entonces más interés en Italia, Francia e Inglaterra. No obstante, algún diario afirmaba que "las estrellas y personalidades del cine norteamericano están pensando en España, y no sólo de forma romántica"66. De hecho por España desfilaron en 1948 Tyrone Power (varias semanas), Rita Hayworth (algunos días), Mary Pickford (algunas horas), María Montez, Walt Disney y, en diciembre de 1948 o enero de 1949 se esperaba la llegada de Eric Johnston, director de la Asociación de Productores. De vuelta de Roma, se aguardaba también la llegada de Gary Cooper e Ingrid Bergman. Todos ellos constataban la popularidad de las películas norteamericanas en España, y los reporteros locales no dudaron en asediar a las estrellas del cine desde el mismo aeropuerto de Barajas. A la popular Mary Pickford un periodista español le preguntó "si era rica", a lo que ella respondió que "no tanto como Ford Jr.". Prometió volver a España y desde la escalinata del avión se despidió con un "viva España".

Las películas norteamericanas venían a ser el $75 \%$ de las que se proyectaban en España ${ }^{67}$, aunque se estrenaban con un retraso de 5 a 6 años (el $40 \%$ eran "westerns"). Lo que entonces preocupaba a la industria cinematográfica estadounidense eran los acuerdos de producción que España había firmado con Argentina y los posibles acuerdos con México ${ }^{68}$, por no hablar de las trabas de todo tipo que interpuso el régimen nacionalista-autárquico. Para agravar aún más la situación, el recién celebrado Certamen Cinematográfico Hispanoamericano en Madrid (27 de junio-5 de julio 1948) logró forzar un decreto del Ministerio de Educación por el que sólo se permitiría el doblaje de tres películas extranjeras por cada una española ${ }^{69}$ (el recurso de las películas subtituladas no era bien recibido por el público) ${ }^{70}$. Sin embargo, a partir de 1952 se abre la vía para las co-producciones, con el rodaje de la película Pandora y el holandés errante de Albert Lewin, seguida de Our Girl Friday de Noel Langley ${ }^{71}$.

En la primavera de 1950 ocurrió algo insólito, por no decir extravagante, para los estadounidenses. Una revista de cine española decidió otorgar el "Óscar español" a Ingrid Bergman y a Ray Milland. El paquete, con estatuillas y todo, fue enviado directamente a Dean Acheson del Departamento de Estado con la solicitud de su

66 Chicago Herald Tribune, Chicago, 10-X-1948.

67 Según el Evening Star, Washington, D.C., 5-X-1948 (en cambio el 5 de julio daba la cifra del $60 \%$ ). LeÓn Aguinaga, 2008, p. 251. Este autor baraja, para Madrid, una cuota de pantalla 65-70\%.

68 Se inserta un informe sobre la mediocridad del cine mexicano en: "Why Mexico is Able to Produce Only a Few Good Films a Year?", Daily Worker, New York, 28-VIII-1950.

69 New York Times, New York, 7-VIII-1948.

70 LeÓn Aguinaga, 2008, ofrece una detallada visión panorámica de los vaivenes de la industria cinematográfica estadounidense en España así como sus objetivos propagandísticos.

71 Losada - Matellano, 2009, pp. 27 y ss. 
entrega a los agraciados cineastas. La primera tentativa del Departamento de Estado fue intentar remitir el paquete a la Motion Picture Associaton of America cuyo responsable respondió con sarcasmo: "Oh no, ese es un bebé para el Departamento de Estado". Al final, "este dolor de cabeza para un ya tribulado Departamento de Estado"72 se resolvió enviando las estatuillas a sendas productoras de los nominados.

En 1950 algunos diarios ${ }^{73}$ informan que Sharman Douglas, la belleza rubia, hija del embajador estadounidense en Londres, debutaría como actriz secundaria en la película That Man from Tangiers, que estaba en pleno rodaje en España. Por otro lado se informa también del rodaje de la película Under Cover, dirigida por Dennis O'Keefe y basada en la novela de Jack Andrews ${ }^{74}$. En mayo de 1951 se rodó también en España Pandora and the Flying Dutchman, dirigida por Albert Lewin y protagonizada por Ava Gardner y James Mason ${ }^{75}$. El contexto del cine español en los años cincuenta cambiaría notablemente, entre otras cosas con una creciente presencia de la industria cinematográfica estadounidense en España ${ }^{76}$.

\section{CONCLUSIONES}

Las relaciones culturales entre España y Estados Unidos se desenvolvieron durante el período objeto de este estudio en un escenario tortuoso marcado por el aislamiento del régimen franquista y por lo intratable que resultaba ser el "caso español" para Estados Unidos. El principal escollo para un acercamiento cultural tenía mucho que ver con el monolitismo con el que el régimen franquista atenazaba todos los poros de una sociedad desprovista de libertades para expresarse libremente. La práctica inexistencia de una sociedad civil hizo que la apuesta cultural de EE.UU. tuviera necesariamente que plantearse un acercamiento al aparato cultural del régimen. Tras la victoria aliada en la Segunda Guerra mundial, pero sobre todo tras el levantamiento del aislamiento internacional en 1948, el aparato cultural del franquismo se "relajó" algo. Sin embargo, las relaciones culturales entre ambos países se desarrollaron sin coherencia; primó más bien la inercia y unas vinculaciones casi irrelevantes. Hasta 1951 la política cultural norteamericana hacia España se había movido titubeante entre el "quiero pero no puedo" y el "puedo pero no quiero". En definitiva, la España franquista no dejaba de ser algo parecido a un "gulag cultural" y una infértil "tierra de misión cultural" para Estados Unidos. La situación cambiaría a partir de 1951 con la normalización de las relaciones diplomáticas y la aproximación entre ambos países al calor de los imperativos derivados de la Guerra Fría.

A continuación reproducimos algunas lecciones que extrae Emmet J. Hughes de las relaciones entre Estados Unidos y España en esos años, que presenta en su obra Report from Spain:

\footnotetext{
72 Es una transcripción del titular del New York Post, New York, 6-IV-1950.

73 New York Post, New York, 8-VIII-1950.

74 New York Post, New York, 8-VIII-1949.

75 Time, 28-V-1951.

76 Losada - Matellano, 2009, p. 35.
} 
Por supuesto no hay duda de que la historia de las relaciones de América con el gobierno de Francisco Franco nos ha dado lecciones importantes y útiles sobre las formas, los problemas y los peligros que existen en nuestras relaciones con otros pueblos y gobiernos del mundo. De estas lecciones podemos sacar provecho. Podemos aprender, aquí y en cualquier lugar, que no existe un lenguaje común por el cual un estado demócrata y uno totalitario puedan hablar y entenderse entre sí. También podemos aprender de la historia de los períodos de Guerra de nuestras relaciones con España, que una opinión pública sabia y madura evita la tentación de emitir juicios demasiado pronto y sin la suficiente información, sobre muchos temas diplomáticos que raras veces son sencillos y sin complicaciones como puede parecer a primera vista. Unos demócratas con formación política se dan cuenta de que no es un privilegio sino un deber de los líderes de la política exterior actuar con frecuencia sobre estos temas sin dar unas explicaciones públicas completas... Nosotros podemos sabiamente recordar que la causa democrática en un país extranjero no está siempre mejor servida por los que son sus más locuaces y entusiastas defensores entre nosotros [...] España, su problema y su tragedia, pone a prueba los principios fundamentales que deben inspirar y animar nuestras relaciones con el resto del mundo. Es un desafío a nuestra comprensión del mundo en que vivimos. Este hecho, en el análisis final, explica porque España importa a los norteamericanos 77 .

\section{REFERENCIAS BIBLIOGRÁFICAS}

Aikman, Duncan

1940 The All-American Front. New York. Doubleday, Daran \& Co. ARNDT, Richard T.

2005 The First Resort of Kings. American Cultural Diplomacy in the

Cull, Nicholas J. Twentieth Century. Washington D.C. Potomac Books.

2008 The Cold War and the United Status Information Agency. American Propaganda and Public Diplomacy, 1945-1989. New York. Cambridge University Press.

Delgado GómEZ-EscaloniLla, Lorenzo

1989 "Las relaciones culturales entre España y Estados Unidos, de la Guerra Mundial a los Pactos de 1953". Cuadernos de Historia Contemporánea. Madrid. no 25, pp. 35-59.

2009a "La maquinaria de la persuasión. Política informativa y cultural de los Estados Unidos hacia España". Ayer. Madrid. no 75, pp. 97-132.

2009b Viento de Poniente: El Programa Fulbright en España. Madrid. Comisión Fulbright.

FEIS, Herbert.

1948 The Spanish Story: Franco and the Nations at War. New York. Alfred A. Knoph.

FolTz, Charles, Jr.

1948 Masquerade in Spain. A Report Unmasking the Rulers of Modern Spain. Cambridge (Mass). The Riverside Press.

${ }^{77}$ Hughes, 1947, pp. 301-302. 
GonzÁlez Cuevas, Pedro Carlos.

1989 "Salvador de Madariaga, pensador político". Revista de Estudios Políticos. Madrid. n 66, pp.145-181.

HAYes, Carlton J. H.

1945 Wartime Mission in Spain. New York. The MacMillan Co.

1951 The U.S. and Spain: An Interpretation. New York. Sheed \& Ward Inc. HIXON, Walter L.

1997 Parting the Curtain. Propaganda, Culture and the Cold War, 19451961. New York. St. Martin's Press.

HoARE, Samuel

1946 Complacent Dictador. New York. Alfred A. Knoph.

HugHES, Emmet John.

1947 Report from Spain. New York. Henry Holt \& Co.

Johnson, Walter - Colligan, Francis.

1965 The Fulbright Program. A History. Chicago, University of Chicago Press.

LeÓn Aguinaga, Pablo

2008 El cine norteamericano y la España franquista, 1939-1960: relaciones internacionales, comercio y propaganda. Tesis Doctoral de la Facultad de Geografía e Historia. Madrid. Universidad Complutense.

2009 "Los canales de propaganda norteamericana en España, 1945-1960". Ayer. Madrid. $\mathrm{n}^{\mathrm{0}}$ 75, pp. 133-158.

Losada, Miguel - Matellano, Victor

2009 El Hollywood español. Madrid. T\&B Editores.

Maestro BÄCKSBacka, Javier - SAgRedo SANTOS, Antonia

2010 "Las relaciones España-EE.UU. en la prensa estadounidense (19471952)”. En SÁnchez Montañés - SÁnchez SuÁrez (eds.), pp. 20-80.

NinKOVICH, Frank A.

1981 The Diplomacy of Ideas: U. S. Foreign Policy and Cultural Relations, 1938-1950. New York. Cambridge University Press.

Niño RodrígueZ, Antonio (ed.)

2009 Uso y abuso de las relaciones culturales en la política internacional. (Dossier sobre La ofensiva cultural norteamericana durante la Guerra Fría). Ayer. Madrid. nº 75, pp. 13-221.

OsGood, Kenneth A.

2006 Total Cold War. Eisenhower's Secret Propaganda Battle at Home and Abroad. Lawrence. University of Kansas Press.

PAINE, Stanley G.

1965 Falange. A History of Spanish Fascism. Paris. Editorial Ruedo Ibérico. PATTEE, Richard

1951 This is Spain. Milwaukee. Bruce Publications.

Pietrangeli, Angelina R.

1960 "John Van Horne (1889-1959)". Hispania. Madrid. no 43-2, pp. 174-175. 
PiZARroso Quintero, Alejandro

2009 Diplomáticos, propagandistas y espias. Estados Unidos y España durante la Segunda Guerra Mundial: información y propaganda. Madrid. CSIC.

SÁnchez MontaÑés, Emma - SÁnchez SuÁrez, María Eugenia (eds.)

2010 Relaciones entre España y Estados Unidos: un acercamiento interdisci plinar. Málaga. Editorial Sepha.

SobrinO, José A.

1952 Introducción crítica a los Estados Unidos. Madrid. Ediciones Cultura Hispánica.

WINKLER, Allan M.

1978 The Politics of Propaganda. The Office of War Information, 1942-1945. New Haven. Yale University Press.

Zulueta, Carmen de

1984 Misioneras, feministas, educadoras. Historia del Instituto Internacional. Madrid. Editorial Castalia. 